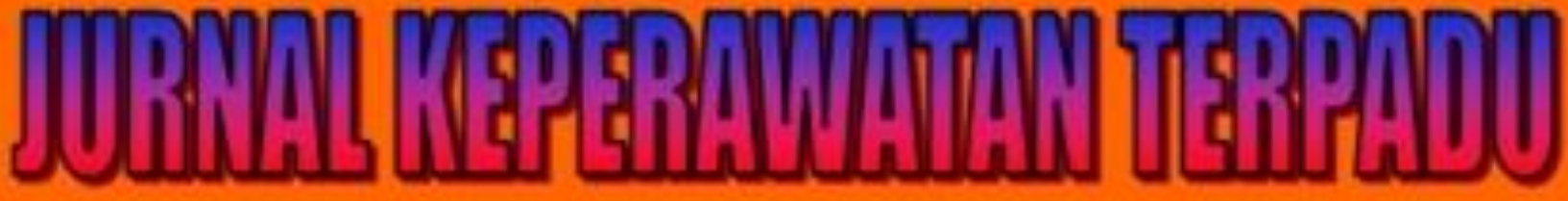

\section{Integrated Nursing Journal}

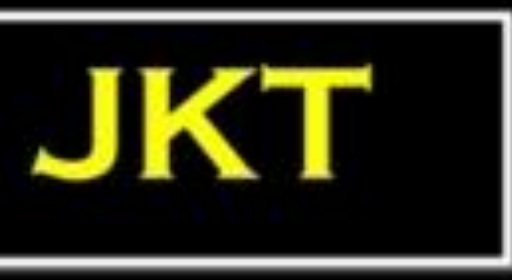

\section{p-ISSN: 2406-9698 (Print) e-ISSN: 2685-0710 (Online)}

\section{Vol. 2 No. 1 April 2020}

\section{KEMENTERIAN KESEHATAN RI}

\section{POLTEKKES MATARAM JURUSAN KEPERAWATAN}

Jalan Kesehatan V/10 Mataram NTB - http://jkt.poltekkes-mataram.ac.id 


\section{Vol. 2 No. 1 April 2020}

\section{Editorial Team}

\section{Editor-in-Chief}

Moh. Arip, Jurusan Keperawatan Poltekkes Kemenkes Mataram, Indonesia

\section{Editorial Board}

1. Mr. Frans Judea Samosir, Universitas Prima Indonesia, Indonesia

2. Baiq Kirana Kitna, Jurusan Keperawatan, Poltekkes Kemenkes Mataram, Indonesia

3. Irwan Budiana, Jurusan Keperawatan, Poltekkes Kemenkes Kupang, Indonesia

4. dr. Baskoro Tri Laksono, RS. Biomedika Mataram, Indonesia

5. Sitti Rusdianah, Jurusan Keperawatan, Poltekkes Kemenkes Mataram, Indonesia

6. Mira Utami Ningsih, Jurusan Keperawatan, Poltekkes Kemenkes Mataram, Indonesia

\section{Alamat Redaksi:}

Jurusan Keperawatan Mataram Poltekkes Kemenkes Mataram Kampus B

Jl. Kesehatan V No.10 Pajang Timur-Mataram NTB-Indonesia, 83127

Telepon: +62 370-621383

Fax: +62 370-631160

Email: jurnalkeperawatanterpadu2019@gmail.com

Laman: http://jkt.poltekkes-mataram.ac.id/index.php/home/index 


\section{Vol. 2, No. 1, April 2020}

\section{DAFTAR ISI}

Pengaruh Self Hypnosis Terhadap Respon Cemas Mahasiswa

Pada Ujian Tahap Akhir Program Di STIKes Buana Husada Ponorogo

Yudha Anggit Jiwantoro, Afifa Ika Kridawati, Danies Tunjung Pratiwi

Efektifitas Tepid Water Sponge Terhadap Penurunan Suhu Tubuh Pada Anak Dengan Masalah Keperawatan Hipertermia: Studi Kasus

Emy Mulyani, Nur Eni Lestari

Perilaku Pencegahan Penyakit Tidak Menular Pada Remaja Ambon

Hamdan Hariawan, Martini Tidore, Greeny Z. Rahakbau

Pengetahuan dan Sikap Perawat Berhubungan dengan Pelaksanaan Patient

Safety

Elisa Sulistia Fitri, Kusnanto, Herdina Maryanti

Efektivitas Art Therapy terhadap Pengetahuan dan Praktik Pemeliharaan Kesehatan Gigi pada Anak Usia Prasekolah

Linda Widyarani, Wiwi Kustio Priliana, Cecilya Kustanti

Konsep Diri Remaja Yang Mengalami Bullying

Puji Lestari, Liyanovitasari

Pengaruh Senam Tai Chi Terhadap Peningkatan Kualitas Tidur Lansia Di Balai Sosial Lanjut Usia Mandalika

Fathaillah Liestanto, Dina Fitriana

Hubungan Komunikasi Terapeutik Perawat Dengan Tingkat Kecemasan

Pasien Hemodialisa Di RSUD Dr Harjono Ponorogo

Ervan Nur Cholis, Rumpiati Rumpiati, Ike Sureni

Upaya Mengatasi Nyeri Post Op Sectio Cesaria Melalui Foot Massage Therapy Diruang Nifas RSUD Kota Mataram

Masadah, Cembun, Ridawati Sulaeman

Peningkatan Pemberdayaan Keluarga Melalui PINKESGA (Paket Informasi Keluarga) Kehamilan Dalam Mengambil Keputusan Merawat Ibu Hamil Mardiatun, Dewi Purnamawati, Ely Mawaddah
Page

$1-6$

Page

$7-14$

Page

$15-21$

Page

22-28

Page

29-39

Page

40-46

Page

$47-53$

Page

54-63

Page

$64-70$

Page

$70-78$ 


\title{
Peningkatan Pemberdayaan Keluarga Melalui PINKESGA (Paket Informasi Keluarga) Kehamilan Dalam Mengambil Keputusan Merawat Ibu Hamil
}

\author{
Mardiatun $^{1}$, Dewi Purnamawati ${ }^{2}$, Ely Mawaddah ${ }^{3}$ \\ Jurusan Keperawatan, Poltekkes Kemenkes Mataram, Indonesia
}

\begin{abstract}
Abstrak
Kehamilan merupakan suatu hal yang sangat penting bagi semua calon ibu,kurangnya pengetahuan serta kurangnya perhatian baik dari diri sendiri, suami maupun keluarga atas kebutuhan saat kehamilan merupakan hambatan bagi seorang ibu dalam menjalani masa kehamilan. Tujuan Penelitian untuk mengetahui pengaruh Pinkesga tentang kehamilan dalam meningkatkan pemberdayaan keluarga dalam mengambil keputuan merawat ibu hamil di Puskesmas Perampuan Labuapi Lombok Barat. Pinkesga diberikan dalam bentuk booklet dan flyer berisi informasi tentang kehamilan dan persalinan. Penelitian ini menggunakan jenis penelitian Quasy eksperiment dengan pretest posttest group design dan menggunakan instrument berupa kuesioner dan lembar observasi checklist. Sebelum diberikan pinkesga, rata-rata nilai responden berada pada kategori tidak mampu (nilai rata-rata 41.8) sedangkan setelah diberikan Pinkesga berada pada kategori mampu (nilai ratarata 86.2). Hasil uji Wilcoxon Signed Ranks Test menunjukkan ada perbedaan antara kemampuan keluarga mengambil keputusan sebelum dan sesudah mendapat Pinkesga kehamilan $(\mathrm{p}=0.000$, $\alpha=0.05$ ). Dapat disimpulkan bahwa pemberian Pinkesga kehamilan dapat meningkatkan kemampuan keluarga dalam mengambil keputusan untuk merawat ibu hamil. Diperlukan model pendekatan yang intensif dalam mengubah kemampuan dan keterlibatan keluarga dalam merawat ibu hamil agar dapat melalui proses kehamilan yang aman dan nyaman.
\end{abstract}

Kata Kunci: Pemberdayaan Keluarga; Pinkesga; Ibu Hamil

\section{Improving Family Empowerment through Pregnancy PINKESGA (Information Package for Family) in Making Decisions to Give Care for Pregnant Mother}

\begin{abstract}
Pregnancy is an important thing for a mother to be. Less of knowledge and less of attention either from the mother herself, husband and families on the needs of mother during pregnancy can be a hindrance for a mother to be to go through her pregnancy. This study aims to identify the effect of pregnancy Pinkesga in improving family empowerment in making decisions to pregnancy care at Parampuan Labuapi, West Lombok. Pinkesga were given to the family in form of booklet and flyer which contain information about pregnancy and delivery. This study is a quasy experiment with prepost test design. Data were collected using questionnaire and observation checklist. Results showed that before given Pinkesga, the mean score of respondents are in the category 'not able' (mean score: 53), while after given Pinkesga, most of respondents are in the category 'able' (mean score: 80). Data analysis using Wilcoxon Signed ranks test with showed that there was a significant difference between the ability of family in making a decision to pregnancy care before given Pinkesga and those after Pinkesga ( $\mathrm{p}=0.000, \alpha=0.05$ ). It can be conclude that Pinkesga can improve the ability of family in making a good decision to give appropriate care for pregnant mother.
\end{abstract}

Keyword: family empowerment; information; health education; pregnant mother 


\section{PENDAHULUAN}

Kehamilan merupakan suatu hal yang sangat penting bagi semua calon ibu, dimana calon ibu pasti akan memberikan perhatian dan perawatan terbaik terhadap kandungannya. Sembilan bulan menjalani masa kehamilan bukanlah hal yang mudah dalam menghadapi dan menjalani kehamilan. Kurangnya pengetahuan tentang kehamilan serta kurangnya perhatian baik dari diri sendiri (ibu hamil), suami maupun keluarga atas kebutuhan saat kehamilan merupakan hambatan bagi seorang ibu dalam menjalani masa kehamilan. Dari waktu ke waktu begitu banyak masalah yang timbul pada wanita yang sangat membutuhan dukungan dari suami maupun keluarga (Susanto, 2013).

Telah banyak dicapai keberhasilan dalam pembangunan nasional di bidang kesehatan, namun bangsa Indonesia masih belum berhasil mencapai "Indonesia Sehat" sebagaimana yang dikehendaki dalam Rencana Pembangunan Jangka Panjang Nasional. Hal yang belum tercapai antara lain, Angka Kematian Ibu masih tinggi, Angka Kematian Bayi juga masih tinggi. Program Indonesia Sehat merupakan salah satu program dari Agenda ke-5 Nawa Cita, yaitu Meningkatkan Kualitas Hidup Manusia Indonesia. Sasaran dari Program Indonesia Sehat adalah meningkatnya derajat kesehatan dan status gizi masyarakat melalui upaya kesehatan dan pemberdayaan masyarakat yang didukung dengan perlindungan finansial dan pemerataan pelayanan kesehatan. Sasaran ini sesuai dengan sasaran pokok RPJMN 2015-2019, yaitu: (1) meningkatnya status kesehatan dan gizi ibu dan anak, (2) meningkatnya pengendalian penyakit, (3) meningkatnya akses dan mutu pelayanan kesehatan dasar dan rujukan terutama di daerah terpencil, tertinggal dan perbatasan, (4) meningkatnya cakupan pelayanan kesehatan universal melalui Kartu Indonesia Sehat dan kualitas pengelolaan SJSN kesehatan, (5) terpenuhinya kebutuhan tenaga kesehatan, obat dan vaksin, serta (6) meningkatnya responsivitas sistem kesehatan. Upaya pencapaian prioritas pembangunan kesehatan tahun 2015-2019 dalam Program Indonesia Sehat dilaksanakan dengan mendayagunakan segenap potensi yang ada, baik dari pemerintah pusat, provinsi, kabupaten/kota, maupun masyarakat. Pembangunan kesehatan dimulai dari unit terkecil dari masyarakat, yaitu keluarga (Kemenkes, 2019).

Angka kematian ibu sudah mengalami penurunan, namun masih jauh dari target Millenium Development Goals (MDGs) tahun 2015, meskipun jumlah persalinan yang ditolong oleh tenaga kesehatan mengalami peningkatan. Kondisi ini kemungkinan disebabkan antara lain oleh kualitas pelayanan kesehatan ibu yang belum memadai, kondisi ibu hamil yang tidak sehat dan faktor determinan lainnya. Penyebab utama kematian ibu adalah hipertensi dalam kehamilan dan perdarahan post partum. Penyebab ini dapat diminimalkan apabila kualitas antenatal care dan peran serta keluarga dalam merawat ibu hamil dilaksanakan dengan baik (PMK.39 thn 2016 tentang Indonesia sehat).

Berdasarkan SDKI 2012 angka kematian ibu di Indonesia sebesar 359 per 100.000 kelahiran hidup. Sedangkan angka kematian ibu di NTB tahun 2012 sebesar 251 per 100.000 kelahiran hidup. 
Berdasarkan laporan dari kabupaten/kota, jumlah kasus kematian ibu di Provinsi NTB selama tahun 2017 adalah 85 kasus, menurun dibandingkan tahun 2016 dengan 92 kasus (Dikes NTB, 2017).

Program Indonesia Sehat dilaksanakan dengan menegakkan tiga pilar utama, yaitu: (1) penerapan paradigma sehat, (2) penguatan pelayanan kesehatan, dan (3) pelaksanaan jaminan kesehatan nasional (JKN). Penerapan paradigma sehat dilakukan dengan strategi pengarusutamaan kesehatan dalam pembangunan, penguatan upaya promotif dan preventif, serta pemberdayaan masyarakat. Penguatan pelayanan kesehatan dilakukan dengan strategi peningkatan akses pelayanan kesehatan, optimalisasi sistem rujukan, dan peningkatan mutu menggunakan pendekatan continuum of care dan intervensi berbasis risiko kesehatan. Sedangkan pelaksanaan JKN dilakukan dengan strategi perluasan sasaran dan manfaat (benefit), serta kendali mutu dan biaya. Kesemuanya itu ditujukan kepada tercapainya keluarga-keluarga sehat (Kemenkes, 2019).

Menyadari permasalahan yang demikian itu, kemenkes membuat telah membuat skala prioritas. Untuk mencapai Indonesia Sehat, dalam kurun waktu 2015-2019, sektor kesehatan diarahkan untuk memfokuskan upaya guna: menurunkan Angka Kematian Ibu dan Angka Kematian Bayi, Menurunkan prevalensi balita pendek (stunting), Menanggulangi penyakit menular HIV-AIDS, Tuberkulosis, dan Malaria dan Menanggulangi penyakit tidak menular Hipertensi, Diabetes, Obesitas, Kanker, dan Gangguan Jiwa. Upaya-upaya tersebut diselenggarakan secara terintegrasi sejak dari perencanaan sampai ke pelaksanaan, pemantauan dan evaluasinya. Sasarannya pun difokuskan kepada keluarga, dengan dihidupkannya kembali "Pendekatan Keluarga" (Kemenkes, 2016). Berdasarkan uraian diatas, maka peneliti tertarik untuk meneliti tentang pengaruh Pinkesga tentang kehamilan dalam meningkatkan pemberdayaan keluarga dalam mengambil keputuan merawat ibu hamil.

\section{METODE}

Penelitian ini menggunakan desain Pre-experimental dengan rancangan one group pretestposttest. Populasi dalam penelitian ini adalah keluarga yang mempunyai anggota keluarga yang sedang hamil dan melakukan pemeriksaan di Puskesmas Perampuan berjumlah 30 responden. Sampel dalam penelitian ini adalah salah satu anggota keluarga yang mempunyai anggota keluarga yang sedang hamil dan melakukan pemeriksaan ANC sebanyak 30 orang yang diambil dengan tehnik purposive sampling atau berdasarkan kriteria inklusi dan eksklusi. Kriteria inklusi diantaranya, keluarga ibu hamil yang sedang hamil trimester 1 dan 2, tinggal bersama keluarga dan melakukan pemeriksaan ANC.

Responden mendapat paket informasi keluarga atau Pinkesga kehamilan, flyer peran keluarga per trimester dan buku saku cara mengatasi ketidaknyamanan ibu hamil. Pemberian Pinkesga dilakukan dalam 4 kali pertemuan. Pada pertemuan pertama, responden mendapat penjelasan tentang Pinkesga dan tujuan penelitian dan mendiskusikan permasalahan terkait peran keluarga selama 
kehamilan kemudian peneliti melakukan pre-test menggunakan checklist peran keluarga per trimester kehamilan. Pada pertemuan kedua, responden mendapat materi awal bimbingan peran keluarga tiap trimester yaitu edukasi perawatan kehamilan dengan melibatkan keluarga meliputi hal-hal yang harus dilakukan ibu hamil tiap trimester dan cara mengatasi ketidaknyamanan ibu hamil tiap trisemester. Kunjungan ketiga, responden kembali mendapat bimbingan terkait pemberdayaan dan keterlibatan keluarga dalam pengambilan keputusan dalam merawat ibu hamil di setiap item peran keluarga tiap trimester. Pada kunjungan keempat, dilakukan evaluasi terhadap kemampuan responden dalam mengambil keputusan dalam merawat ibu hamil menggunakan checklist checklist peran keluarga per trimester kehamilan. Kunjungan ini merupakan kunjungan untuk post test. Selanjutnya dilakukan kunjungan kelima untuk mengevaluasi kunjungna ANC yang sudah di lakukan berdasarkan kunjungan nasional yang seharusnya di lakukan dan evaluasi keterlibatan keluarga dalam pendampingan ibu hamil dalam kelas ibu hamil.

Data peningkatan kemampuan keluarga dalam mengambil keputusan untuk merawat ibu hamil dikategorikan mampu dan tidak mampu. Data dianalisa dengan menggunakan uji Wilcoxon Signed Ranks Test untuk membandingkan data pre dan post test.

\section{HASIL PENELITIAN}

Tabel 1. Distribusi frekuensi responden berdasarkan pendidikan, usia, kelas ibu hamil dan kepemilikan buku KIA di Puskesmas Perampuan NTB Bulan Agustus - Oktober 2019

\begin{tabular}{|c|c|c|c|}
\hline NO & Karakteristik & Perlakuan $(n=30)$ & Persentase \\
\hline \multirow[t]{5}{*}{1} & Pendidikan & & \\
\hline & Dasar & 5 & $16,7 \%$ \\
\hline & Menengah & 17 & $56,7 \%$ \\
\hline & Lanjutan & 6 & $20 \%$ \\
\hline & Tdk sekolah & 2 & $6 \%$ \\
\hline \multirow[t]{4}{*}{2} & Umur & & \\
\hline & $20-25$ tahun & 3 & $0.1 \%$ \\
\hline & 26 - 30 tahun & 12 & $40 \%$ \\
\hline & $31-35$ tahun & 15 & $50 \%$ \\
\hline \multirow[t]{6}{*}{3} & Pekerjaan & & \\
\hline & PNS & 3 & $10 \%$ \\
\hline & Wiraswasta & 12 & $40 \%$ \\
\hline & Buruh atau petani & 12 & $40 \%$ \\
\hline & Tidak bekerja & 1 & $3 \%$ \\
\hline & & 2 & $7 \%$ \\
\hline \multirow[t]{3}{*}{4} & Paritas & & \\
\hline & Primi & 11 & $37 \%$ \\
\hline & Multi & 19 & $63 \%$ \\
\hline
\end{tabular}




\begin{tabular}{llcc}
\hline $\mathbf{5}$ & Kelas ibu hamil & & \\
& Iya & 1 & $3 \%$ \\
& Tidak & 29 & $97 \%$ \\
\hline $\mathbf{6}$ & Memiliki buku KIA & 30 & $100 \%$ \\
& Iya & 0 & $0 \%$ \\
& Tidak & & \\
\hline $\mathbf{7}$ & Penyakit penyerta & 4 & $13 \%$ \\
& Iya & 26 & $87 \%$ \\
& Tidak & 30 & $100 \%$ \\
& Total & \\
\hline
\end{tabular}

Berdasarkan Tabel di atas dapat diketahui jumlah kelompok Pendidikan, umur, pekerjaan, paritas, kelas ibu hamil, kepemilikan buku KIA dan penyakit penyerta pada responden. Pendidikan responden terbanyak adalah 17 orang (56.7\%) kelompok pendidikan menengah. Kelompok pekerjaan responden terbanyak 25 orang (83\%) adalah kelompok Wiraswasta. Kelompok Paritas responden terbanyak adalah 18 orang (60\%) adalah Multigravida Kelompok Kelas Ibu Hamil terbanyak adalah sebanyak 16 orang (53\%) adalah tidak mengikuti kelas ibu hamil. Kepemilikan buku KIA responden terbanyak adalah sebanyak 30 (100\%) memiliki buku KIA. Riwayat penyakit responden terbanyak adalah 28 (93\%) yaitu tidak memiliki riwayat penyakit penyerta.

Tabel 2. Hasil uji Wilcoxon Signed Ranks Test data pre dan post test

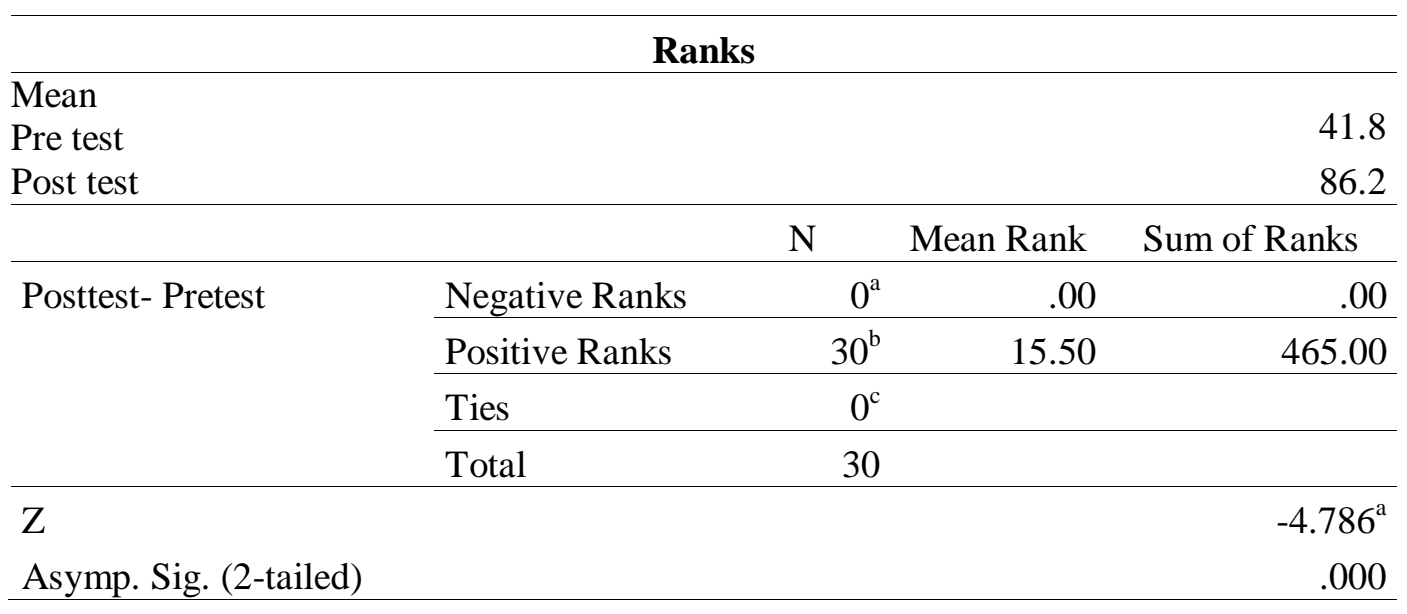

Hasil penelitian menunjukkan bahwa skor rata-rata responden pada pretest berada pada kategori tidak mampu (skor rata-rata: 41,8) dan skor rata-rata responden pada post test adalah termasuk dalam kategori mampu (skor rata-rata: 86.2). Hasil uji uji Wilcoxon Signed Ranks Test diperoleh nilai $\mathrm{p}(0,000)<0,05$ yang berarti terdapat perbedaan kemampuan keluarga dalam mengambil keputusan untuk perawatan ibu hamil sebelum dan sesudah mendapatkan Pinkesga kehamilan. 


\section{PEMBAHASAN}

Tidak semua keluarga memiliki koping yang efektif atau kompeten dalam menghadapi masalah anggota keluarga. Nanda (2012), menjelaskan masalah penurunan koping keluarga sebagai ketidakadekuatan dan ketidakefektifan keluarga membantu klien untuk mengelola dan menguasai tugas adaptif terkait masalah kesehatan. Hal ini disebabkan karena beberapa faktor yang berhubungan antara lain; menghabiskan kemampuan suportif dari keluarga, kurangnya informasi pada keluarga, sakit yang berlangsung lama tidakadekuatnya pemahaman keluarga dan informasi yang tidak benar kepada keluarga tentang masalah kesehatan yang dihadapi keluarga (NANDA, 2012).

Salah satu penyebab kurangnya peran keluarga dalam penelitiian ini adalah kurangnya informasi yang di peroleh keluarga di karenakan kurangnya imformasi dan keikutsertaan yang kurang dalam kelas ibu hamil terutama pada kelompok control. Salah satu alasan ketidakikutsertaan ibu hamil adalah karena kesibukan mengurus rumah untuk ibu hamilnya dan merasa itu bukan bagian dari kewajiban suami dalam mengikuti kelas ibu hamil ketika mendampingi ibu hamil, padahal dari kelas ibu hamil akan banyak di peroleh infromasi mengenai perawatan kehamilan dan persalinan.

Perbedaan yang di tunjukkan dalam hasil penelitian ini peningkatan kemampuan dalam pemberdayaan setelah perlakuan. Hal tersebut di karenakan adanya kepemilikan buku KIA dan adanya bimbingan dan pendampingan dari peneliti menggunakan buku KIA tersebut yang di sinkronkan dengan adanya informasi dari buku Pinkesga (Paket Informasi Keluarga) tiap trimester yang sudah di buat peneliti untuk membantu hal hal apa saja yang bisa dilakukan/keterlibatan keluarga sesuai dengan Trimester yang di butuhkan ibu hamil dan cara mengatasi keluhan ketidaknyamanan yang di rasakan.

Pada pre dan post test terdapat selisih peningkatan rata - rata 45,4. Skor setelah di lakukan pemberdayaan keluarga melalui Pinkesga kehamilan lebih tinggi ketimbang skor sebelum dilakukan Pinkesga kehamilan. Hasil penelitian sebelum dilaksanakan intervensi, di peroleh data yaitu dari 30 responden ada 1 responden yang mampu. Ini berarti hanya sedikit responden atau keluarga yang memiliki keterlibatan dalam merawat ibu hamil.

Pemberdayaan keluarga adalah intervensi keperawatan yang dirancang dengan tujuan untuk mengoptimalkan kemampuan keluarga, sehingga anggota keluarga memiliki kemampuan secara efektif merawat anggota keluarga dan mempertahankan kehidupan mereka (Ardian, 2014). Pemberdayaan Keluarga merupakan mekanisme yang memungkinkan terjadinya perubahan kemampuan keluarga sebagai dampak positif dari intervensi keperawatan yang berpusat pada keluarga dan tindakan promosi kesehatan serta kesesuaian budaya yang mempengaruhi tindakan pengobatan dan perkembangan keluarga (Graves, 2007). 
Konsep Pemberdayaan Keluarga memiliki tiga komponen utama. Pertama, bahwa semua keluarga telah memiliki kekuatan dan mampu membangun kekuatan itu. Kedua, kesulitan keluarga dalam memenuhi kebutuhan mereka bukan karena ketidakmampuan untuk melakukannya, melainkan sistem pendukung sosial keluarga tidak memberikan peluang keluarga untuk mencapainya. Ketiga, dalam upaya pemberdayaan keluarga, anggota keluarga berupaya menerapkan keterampilan dan kompetensi dalam rangka terjadinya perubahan dalam keluarga (Graves, 2007).

Hasil penelitian menunjukkan kurangnya dukungan keluarga khususnya dalam keterlibatan suami dalam kelas ibu hamil adalah kurangnya dukungan social dari masing-masing suami/keluarga karena menganggap kelas ibu hamil hanya untuk ibu hamil saja dan karena melihat para pasangan/suami ibu hamil yang lain hanya mengantar saja tapi tidak ikut dalam kegiatan padahal 1-2 kali kehadiran suami di butuhkan terutama pembinaan dalam pengambilan keputusan dalam kelas ibu hamil. Perubahan kemampuan dalam pemberdayaan kelurga dalam merawat ibu hamil setelah di lakukan intervensi karna sudah di lakukan pembinaan lansung oleh peneliti menggunakan buku KIA yang ada pada ibu hamil yang telah di sinkronkan dengan isi Pinkesga yang berisi peran keluraga dalam mendampingi ibu hamil tiap trimester sehingga lebih memudahkan dalam mengambil keputusan dan merencanakan untuk melakukan yang seharusnya di lakukan tiap trimester oleh ibu hamil sehingga ada timbal balik dengan apa yang akan di lakukan oleh ibu hamil dan peran kelurga dalam setiap tindakan pencegahan dan tindakan yang seharusnya di lakukan di laksanakan

\section{Pelaksanaan pemeriksaan kehamilan/Kunjungan ANC ibu hamil}

Hasil penelitian menunjukkan bahwa pelaksanaan kunjungan Antenatal care (ANC) atau pemeriksaan kehamilan responden sebelum dan setelah post test pada responden di peroleh $100 \%$ sesuai jadual kunjungan yang di sarankan WHO yaitu 4x selama kehamilan bahkan lebih dari 4 kali.

Kunjungan ANC adalah kunjungan ibu hamil ke petugas kesehatan sedini mungkin semenjak ia merasa dirinya hamil untuk mendapatkan pelayanan /asuhan antenatal. Pada setiap kunjungan Antenatal Care (ANC), petugas mengumpulkan dan menganalisis data mengenai kondisi ibu melalui anamnesis dan pemeriksaan fisik untuk mendapatkan diagnosis kehamilan intrauterine serta ada tidaknya masalah atau komplikasi (Saifudin, 2005). WHO menyarankan agar setiap ibu hamil melakukan pemeriksaan kehamilan minimal 4kali pertemuan yaitu satu kali pada trisemester pertama, satu kali pada trisemster kedua dan dua kali pada trisemester ketiga.. Optimal dilakukan delapan kali selama kehamilan yaitu setiap 4 minggu sekali dari saat pemeriksaan kehamilan pertama kali hingga usia kehamilan 28 minggu, setiap 2 minggu sekali dari usia kehamilan 28-36 minggu dan setiap satu minggu sekali dari usia kehamilan 36 minggu hingga waktunya melahirkan (Gaither, 2016). 
Berdasarkan wawancara dan observasi yang dilakukan peneliti dari beberapa resonden yang melakukan ANC. Rata-rata kunjungan ANC yang dilakukan lebih dari 4 kali beberapa responden memilih tiap bulan periksa kehamilannya ke posyandu, hal tersebut di lihat dari hasil pemeriksaan yang sudah dilakukan di buku KIA. Di samping itu juga adanya dukunga dari pihak puskesmas yang menjadualkan posyandu tiap bulan $\mathrm{n}$ membuat kelas ibu hamil, akan tetapi keterlibatan keluarga yang kurang dalam kelas ibu hamil tersebut dikarenakan semua responden atau keluarga mengganggap perannya tidak di butuhkan dan alasan kesibukan tapi dengan adanya ceklist peran yang sudah di buat peneliti akan membantu keluarga dalam mengambil keputusan akan peran yang seharusnya dilakukan dan saat di butuhkan, ini terbukti dari hasil penelitian di mana keterlibatan keluarga yang kurang $(0,3 \%)$ sebelum perlakuan menjadi meningkat $(53 \%)$ dan sebagian besar di lakukan oleh suami ibu hamil.

\section{KESIMPULAN}

Dari hasil penelitian disimpulkan bahwa terdapat perbedaan kemampuan keluarga dalam mengambil keputusan untuk merawat ibu hamil sebelum diberikan Pinkesga dengan kemampuan setelah diberikan Pinkesga kehamilan. Setelah diberikan Pinkesga kehamilan, rata-rata kemampuan keluarga meningkat menjadi kategori 'mampu.' Peningkatan pemberdayaan keluarga dapat dilakukan dengan pemberian Pinkesga kehamilan. Sehingga diharapkan pemberian Pinkesga kehamilan ini dapat diberikan oleh instansi pelayanan kesehatan primer seperti Puskesmas kepada semua keluarga ibu hamil di wilayah kerjanya.

\section{DAFTAR PUSTAKA}

Ardian, I. (2014). Pemberdayaan Keluarga (Family Empowerment) sebagai Intervensi Keperawatan Keluarga. Majalah Ilmiah Sultan Agung, Vol. 52(No. 133), 41-54. Retrieved from http://research.unissula.ac.id/file/publikasi/210997003/4129artikel_pemberdayaan.pdf

Ardian Iwan (2013), Pemberdayaan Keluarga (Family Empowerment) Meningkatkan Koping Keluarga Diabetes Militus Tipe-2. Jurnal Ilmu Keperawatan - Volume 1, No. 2, Nopember 2013. www.jik.ub.ac.id

DinKes Kota Mataram. (2015). Pofil Kesehatan Kota Mataram Tahun 2015.

Friedman, M.M., Bowden, V.R., \& Jones, E. G. (2010). Buku ajar keperawatan keluarga: Riset, Teori, praktek. Jakarta

Gaither, K WebMD (2016). Your First Prenatal Doktor's Visit

Kemenkes (2019) Pedoman Umum Program Indonesia Sehat Dengan Pendekatan Keluarga Http://www.depkes.go.id/resources/ download/ lain/Buku \%20Program\% 20Indonesia\% 20Sehat\%20dengan\%20 Pendekatan\%20 Keluarga. Pdf

Vol. 2 No. 1 (2020); APRIL 
Peraturan Menteri Kesehatan Republik Indonesia Nomor 39 Tahun (2016) Tentang Pedoman Penyelenggaraan Program Indonesia Sehat.

Susanto, Hermawan (2013) Aplikasi Panduan Untuk Ibu Hamil Berbasis Android Mobile. Skripsi thesis, Universitras Muhammadiyah Surakarta. 